\title{
EVALUASI TINGKAT KEMATANGAN \\ PROSES DELIVERY AND SUPPORT PADA IMPLEMENTASI \\ SISTEM INFORMASI AKADEMIK UNIVERSITAS NEGERI PADANG \\ BERDASARKAN KERANGKA KERJA COBIT 4.0
}

\author{
Syukhri ${ }^{1}$, Nizwardi Jalinus ${ }^{2}$, Ganefri ${ }^{3}$ \\ Program Studi Pendidikan Teknologi dan Kejuruan \\ Fakultas Teknik Universitas Negeri Padang \\ Email:syukhri@gmail.com
}

\begin{abstract}
Abstrak
Penelitian ini dilakukan untuk mengetahui tingkat kematangan proses penyampaian dan dukungan (Delivery and Support) pada implementasi Sistem Informasi Akademik Universitas Negeri Padang, sesuai kriteria pada Control Objectives for Information and Related Technology (COBIT). Proses yang dievaluasi adalah (1) memastikan pelayanan yang berkesinambungan, (2) pengelolaan layanan bantu, dan (3) pengelolaan data. Metode yang dilakukan pada penelitian ini adalah dengan pengisian kuesioner terhadap subjek penelitian sesuai pemetaan diagram RACI, serta pengamatan langsung terhadap Sistem Informasi Akademik Universitas Negeri Padang. Temuan penelitian menunjukkan tingkat kematangan pada proses memastikan pelayanan yang berkesinambungan, pengelolaan layanan bantu, dan pengelolaan data pada implementasi Sistem Informasi Akademik Universitas Negeri Padang berada pada tingkat 3 (proses terdefinisi). Hasil evaluasi tingkat kematangan tersebut menjadi dasar dalam menentukan usulan upaya perbaikan kepada pihak manajemen Universitas Negeri Padang sehingga dapat meningkatkan layanan.
\end{abstract}

\begin{abstract}
This study was conducted to determine maturity level of Delivery and Support process on the implementation of the Academic Information System Padang State University, according to the criteria in the Control Objectives for Information and Related Technology (COBIT). Processes evaluated were (1) Ensure Continuous Service, (2) Manage Service Desk and Incidents, and (3) Manage Data. The method used in this study is a questionnaire with the appropriate research subjects RACI diagram mapping, and direct observation of Academic Information Systems, State University of Padang. The findings showed the maturity level of the process ensure continuous service, manage service desk and incidents, and manage data in the implementation of the Academic Information System Padang State University is located on level 3 (the process is defined). Results of evaluation of the maturity level is fundamental in determining the proposed improvements to the management of the State University of Padang in order to improve the service.
\end{abstract}

Keywords: IT Evaluation, Academic Information System, COBIT, Maturity

\section{A. Pendahuluan}

Teknologi informasi (TI) mengalami perkembangan yang sangat pesat dalam dekade terakhir. Peranan TI sangat besar dan menjadi urat nadi dalam proses bisnis dan manajemen organisasi modern. Hal ini berlaku umum baik bagi organisasi profit maupun organisasi non profit termasuk organisasi di dunia pendidikan. Khusus di dunia pendidikan, implementasi TI pada perguruan tinggi memberikan perubahan yang signifikan dalam memberikan pelayanan kepada civitas akademika mereka.

Universitas Negeri Padang (UNP) merupakan salah satu perguruan tinggi negeri eksIKIP yang memperoleh perluasan mandat (wider mandate) menjadi universitas. UNP saat ini memiliki dan menyelenggarakan program studi non kependidikan disamping program studi 
kependidikan. Kondisi ini berakibat pada peningkatan jumlah program studi, fakultas, dosen dan mahasiswa yang signifikan. Saat ini jumlah mahasiswa aktif di UNP adalah sebanyak 33.045 orang yang tersebar di 101 program studi baik jenjang pendidikan diploma, sarjana dan pasca sarjana. Sedangkan jumlah dosen tetap saat ini 929 orang (UPT. Pusat Komputer UNP, 2012). Peningkatan jumlah program studi, dosen dan mahasiswa tersebut sangat berpengaruh kepada proses pelayanan akademik. Dengan jumlah entitas yang besar ini dibutuhkan cara pengelolaan proses akademik yang efektif, efisien, terintegrasi dan mudah diakses dengan validitas data yang tetap terjaga serta mutu pelayanan yang baik.

Salah satu cara untuk mencapai hal tersebut adalah melalui pemanfaatan TI. Pemanfaatan TI secara global terbukti dapat menjadikan proses kerja organisasi menjadi lebih efektif dan efisien. Pada tahun 2005 berbagai jenis aplikasi dan sistem informasi mulai dikembangkan di UNP demi menunjang pekerjaan. Semua aplikasi tersebut diintegrasikan dalam satu kesatuan sistem yang kemudian disebut aplikasi SmartCampus.

Dari sekian banyak aplikasi yang telah dikembangkan, salah satunya adalah Sistem Informasi Akademik (SIA). SIA adalah perangkat unsur yang secara teratur saling berkaitan sehingga menghasilkan informasi akademik. SIA bertujuan untuk mendukung penyelenggaraan pendidikan, sehingga perguruan tinggi dapat menyediakan layanan informasi yang lebih baik dan efektif kepada komunitasnya baik di dalam maupun di luar perguruan tinggi tersebut.

Sejauh ini penerapan SIA sangat membantu proses akademik di tingkat fakultas, jurusan, program studi, dosen maupun mahasiswa. Namun di sisi lain penerapan SIA masih memiliki permasalahan yang mengganggu kenyamanan pengguna. Dari hasil pengamatan, beberapa permasalahan yang sering muncul adalah akses ke SIA yang seringkali lambat bahkan putus terutama pada periode-periode padat aktifitas, seperti periode LHS maupun KRS yang mengakibatkan data tidak dapat diakses. Selain itu peranan layanan bantu untuk mengatasi permasalahan tersebut masih dirasa kurang.

Berdasarkan uraian di atas, perlu dilakukan evaluasi untuk menilai sejauhmana setiap proses TI pada SIA berfungsi sesuai dengan tujuan pengembangan aplikasi terutama untuk proses memastikan pelayanan yang berkesinambungan, pelayanan bantu dan pengelolaan data. Hasil evaluasi dapat digunakan untuk melakukan perbaikan dan peningkatan layanan SIA di UNP.

Ada banyak standar evaluasi TI yang dapat digunakan untuk mengevaluasi tata kelola layanan TI, antara lain The IT Infrastruktur Library (ITIL), ISO/IEC 17799, Committee of Sponsoring Organization of the Treadway Commission (COSO) dan Control Objectives for Information and Related Technologies (COBIT). Masing-masing standar memiliki kelebihan dan kekurangan masing-masing. Menurut IT Governance Institute, (2006:71) COBIT mempunyai kompromi antara dimensi detil atau kedalaman standar dalam hal teknis dan operasional serta kelengkapan proses TI yang lebih baik dibandingkan standar-standar lainnya.

Lebih jauh IT Governance Institute, (2006:71) menyatakan COBIT mempunyai spektrum proses TI yang lebih luas dan lebih mendetil. ITIL merupakan standar yang paling mendetil dalam mendefinisikan proses-proses TI yang bersifat teknis dan operasional. Sedangkan COSO mempunyai detil yang dangkal, walaupun spektrum proses teknis dan operasionalnya cukup luas. Berdasarkan kelebihan dan kekurangan masing-masing standar tersebut, penelitian ini menggunakan standar kerangka kerja COBIT. Faktor lain pemilihan COBIT adalah karena COBIT bersifat universal sehingga dapat diaplikasikan pada semua jenis organisasi.

\section{B. Metode Penelitian}

Penelitian ini menggunakan metode studi evaluasi untuk menilai suatu program yang sedang atau sudah dilakukan. Hasil dari penelitian ini digunakan untuk perbaikan atau peningkatan program-program tersebut. Penelitian studi evaluasi adalah jenis penelitian deskriptif yang berusaha menyajikan fakta-fakta aktual dan sifat populasi tertentu secara sistematis dan akurat. Menurut Sukardi (2009:14), penelitian deskriptif adalah penelitian yang 
berusaha menggambarkan kegiatan penelitian. Penelitian deskriptif ini juga disebut penelitian pra eksperimen karena dalam penelitian ini dilakukan eksplorasi, menggambarkan, dengan tujuan untuk dapat menerangkan dan memprediksi terhadap suatu gejala yang berlaku atas dasar data yang diperoleh di lapangan.

Pengumpulan data dilakukan melalui kuisioner yang dikembangkan berdasarkan model kematangan COBIT 4.0 dan dikaitkan dengan atribut kematangan yang mempengaruhinya. Kuisioner kemudian di ujicoba untuk menguji validitas dan reliabilitasnya. Apabila hasil ujicoba menyatakan kuisioner tidak valid, maka kuisioner harus diperbaiki dan di ujicoba kembali sampai semua butir pernyataan dinyatakan valid. Kuisioner yang valid kemudian diberikan kepada subjek penelitian untuk diisi. Subjek penelitian adalah pihak-pihak yang terlibat dan bertanggungjawab dalam implementasi SIA UNP mengacu pada diagram RACI dalam panduan COBIT 4.0.

Tabel 1. Subjek Penelitian

\begin{tabular}{|c|c|c|c|}
\hline No & $\begin{array}{l}\text { RACI Diagram } \\
\quad(\text { COBIT })\end{array}$ & $\begin{array}{c}\text { Jabatan Subjek Penelitian } \\
\text { (UNP) }\end{array}$ & Jumlah \\
\hline 1. & CEO & Rektor & 1 \\
\hline 2. & CFO & Kepala BAUK & 1 \\
\hline 3. & Business Executive & Kepala BAAK & 1 \\
\hline 4. & $\mathrm{CIO}$ & Kepala UPT Puskom & 1 \\
\hline 5. & Business Process Owner & $\begin{array}{l}\text { Kabag Akademik dan } \\
\text { Kerjasama }\end{array}$ & 1 \\
\hline 6. & Head Operations & $\begin{array}{l}\text { Pembantu Dekan Bidang } \\
\text { Akademik, Ketua Jurusan }\end{array}$ & 10 \\
\hline 7. & Chief Architect & $\begin{array}{l}\text { Staf Teknis UPT Puskom } \\
\text { (System Administrator, Network } \\
\text { Administrator, Data Manager, } \\
\text { Programmer) }\end{array}$ & 5 \\
\hline 8. & Head Development & Kepala BAPSI & 1 \\
\hline 9. & Head IT Administration & $\begin{array}{l}\text { Kepala Sub Bagian Tata Usaha } \\
\text { UPT Puskom }\end{array}$ & 1 \\
\hline 10. & $\begin{array}{l}\text { Compliance, Audit, Risk } \\
\text { and Security }\end{array}$ & Auditor Internal & 2 \\
\hline 11. & $\begin{array}{l}\text { Service Desk / Incident } \\
\text { Manager }\end{array}$ & Administrator Fakultas & 7 \\
\hline \multicolumn{3}{|c|}{ Jumlah } & 31 \\
\hline
\end{tabular}

Data yang terkumpul melalui kuisioner kemudian dianalisis sehingga dapat diinterpretasikan. Analisis yang dilakukan meliputi deskripsi data, analisis tingkat kematangan dan analisis kesenjangan. Analisis tingkat kematangan dilakukan menggunakan metode Pederiva, (2003:2). Setelah diketahui tingkat kematangan setiap proses yang diteliti, selanjutnya dilakukan analisis kesenjangan. Analisis kesenjangan membandingkan tingkat kematangan yang dicapai saat ini (as-is) dengan tingkat kematangan yang berada satu tingkat diatasnya (to-be). Untuk lebih jelasnya, desain penelitian dapat dilihat pada Gambar 1. 


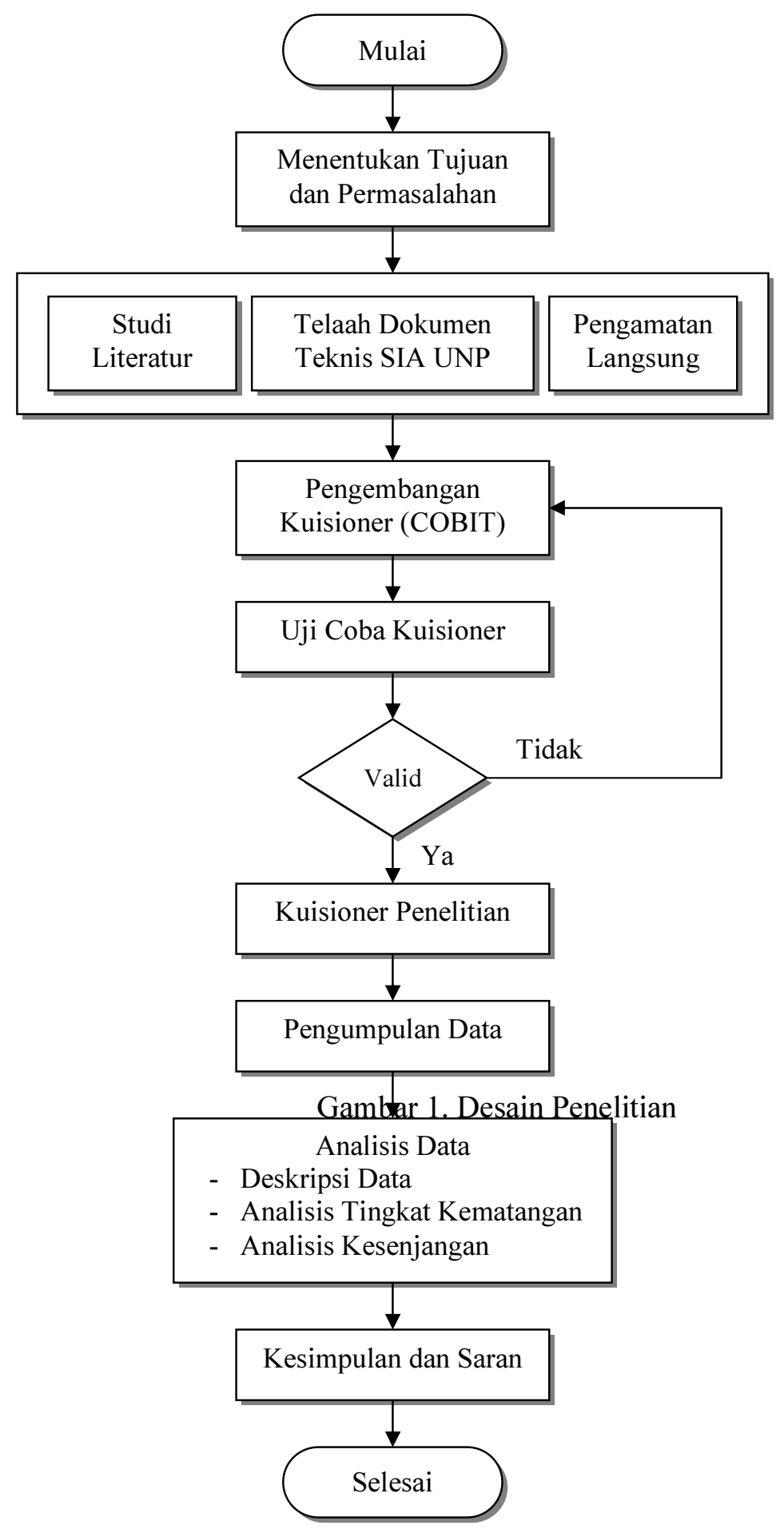




\section{Hasil dan Pembahasan}

\section{Hasil}

Penelitian ini membedakan antara nilai kematangan dan tingkat kematangan. Menurut Kridanto Surendro, (2009:284) nilai kematangan merepresentasikan proses pencapaian menuju tingkat kematangan tertentu. Nilai kematangan tidak mutlak berbentuk bilangan bulat, bisa saja berbentuk bilangan pecahan. Sedangkan tingkat kematangan lebih menunjukkan tingkatan atau kelas yang dicapai dalam proses kematangan dan dinyatakan dalam bilangan bulat. Hubungan antara nilai kematangan dan tingkat kematangan dapat dilihat pada Tabel 2 berikut ini:

Tabel 2. Hubungan Nilai Kematangan dan Tingkat Kematangan

\begin{tabular}{|c|l|}
\hline Nilai Kematangan & \multicolumn{1}{|c|}{ Tingkat Kematangan } \\
\hline $0.00-0.50$ & $0-$ Non Existent \\
\hline $0.51-1.50$ & $1-$ Initial / Adhoc \\
\hline $1.51-2.50$ & $2-$ Repeatable but Intuitive \\
\hline $2.51-3.50$ & $3-$ Defined Process \\
\hline $3.51-4.50$ & $4-$ Managed and Measurable \\
\hline $4.51-5.00$ & $5-$ Optimized \\
\hline
\end{tabular}

Sumber: COBIT 4.1 IT Governance (2007)

Nilai kematangan diperoleh menggunakan metode Pederiva, (2003:2). Berdasarkan metode tersebut diperoleh nilai kematangan untuk DS4 sebesar 2.6761, DS8 2.5656 dan DS11 2.5456. Mengacu pada tabel 2, dapat disimpulkan bahwa DS4, DS8 dan DS11 pada proses implementasi SIA UNP berada pada tingkat kematangan 3 sebagaimana direpresentasikan pada Tabel 3.

Tabel 3. Hubungan Nilai Kematangan dan Tingkat Kematangan

\begin{tabular}{|l|c|c|}
\hline \multicolumn{1}{|c|}{ Proses TI } & $\begin{array}{c}\text { Nilai } \\
\text { Kematangan }\end{array}$ & $\begin{array}{c}\text { Tingkat } \\
\text { Kematangan }\end{array}$ \\
\hline $\begin{array}{l}\text { Memastikan Pelayanan yang } \\
\text { Berkesinambungan (DS4) }\end{array}$ & 2.6761 & 3 \\
\hline Pengelolaan Layanan Bantu (DS8) & 2.5656 & 3 \\
\hline Pengelolaan data (DS11) & 2.5456 & 3 \\
\hline
\end{tabular}

\section{Pembahasan}

Tingkat kematangan dipengaruhi oleh beberapa atribut, yaitu kepedulian dan komunikasi (Awareness and Communication - AC), kebijakan, standar dan prosedur (Policy, Standard and Procedures - PSP), tanggungjawab dan akuntabilitas (Responsibility and Accountability - RA), perangkat bantu dan otomasi (Tools and Automation - TA), keterampilan dan keahlian (Skills and Expertise - SE) serta penetapan tujuan dan pengukuran (Goal Setting and Measurement - GSM). Berdasarkan distribusi data hasil penelitian, diperoleh capaian untuk tiap atribut kematangan sebagaimana tertuang pada Tabel 4.

Berdasarkan analisis tingkat kematangan yang telah dilakukan sebelumnya, diketahui proses DS4, DS8 dan DS11 berada pada tingkat kematangan 3 (proses terdefinisi). 
Mengacu pada tingkat kematangan as-is, target tingkat kematangan to-be diarahkan menjadi tingkat kematangan 4 (terkelola dan terukur). Dengan membandingkan tingkat kematangan $a s-i s$ dengan target tingkat kematangan to-be, akan diperoleh kesenjangan. Untuk menutupi kesenjangan tersebut, perlu upaya perbaikan sebagaimana yang ditunjukan dengan pergerakan arah bintang dari bawah ke atas. Gambaran tingkat kematangan as-is, to-be, kesenjangan dan upaya perbaikan direpresentasikan pada Tabel 5 dan Gambar 5.

Tabel 5. Kesenjangan Tingkat Kematangan as-is dan to-be

\begin{tabular}{|l|c|c|c|}
\hline \multirow{2}{*}{\multicolumn{1}{|c|}{ Proses TI }} & \multicolumn{2}{c|}{$\begin{array}{c}\text { Tingkat } \\
\text { Kematangan }\end{array}$} & \multirow{2}{*}{ Kesenjangan } \\
\cline { 2 - 3 } & as-is & to-be & \\
\hline $\begin{array}{l}\text { Memastikan Pelayanan yang } \\
\text { Berkesinambungan (DS4) }\end{array}$ & 3 & 4 & 1 \\
\hline Pengelolaan Layanan Bantu (DS8) & 3 & 4 & 1 \\
\hline Pengelolaan data (DS11) & 3 & 4 & 1 \\
\hline
\end{tabular}

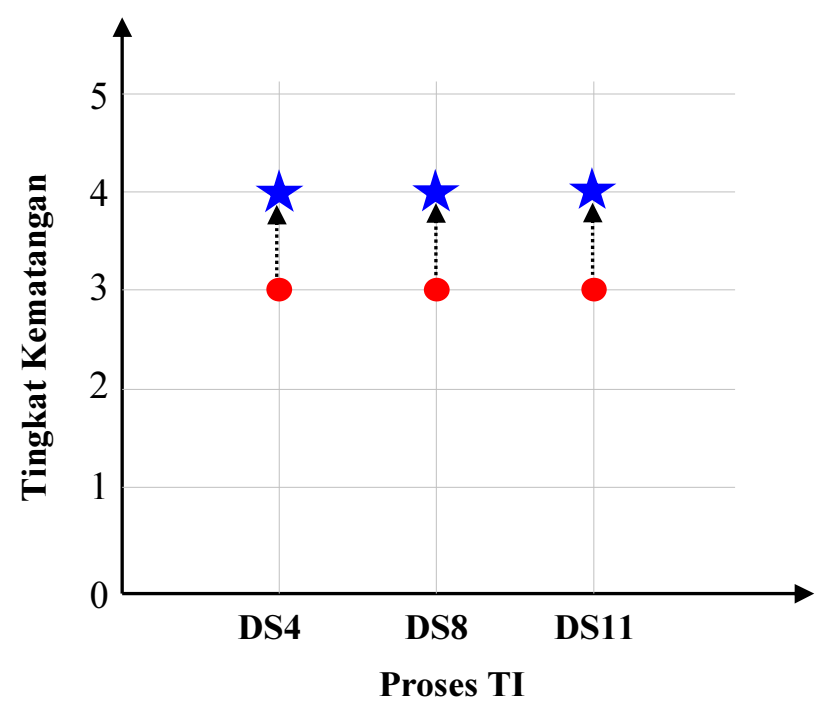

$\begin{array}{ll}\text { Keterangan } & \text { Tingkat kematangan saat ini }(a s-i s) \\ & \text { Tingkat kematangan yang ingin dicapai }(t o-b e) \\ \text { Upaya pencapaian tingkat kematangan yang ingin dicapai }\end{array}$

Gambar 5. Pergerakan Tingkat Kematangan as-is ke Tingkat Kematangan to-be

Berdasarkan Tabel 4, dapat dilihat bahwa beberapa atribut yang mempengaruhi tingkat kematangan proses DS4, DS8, DS11 masih belum dilaksanakan secara optimal. Untuk meningkatkan kematangan proses DS4, DS8 dan DS11 yang saat ini berada pada tingkat 3 (proses terdefinisi) menjadi tingkat 4 (terkelola dan terukur), perlu dilakukan upaya perbaikan.

Upaya perbaikan dilakukan mengacu pada model kematangan yang telah didefinisikan dalam COBIT. Untuk mencapai tingkat kematangan 4, upaya perbaikan diarahkan pada proses TI yang terarah, terkelola dengan baik dan terukur sesuai model kematangan pada COBIT yang dituangkan dalam bentuk matrik upaya perbaikan. Matrik upaya perbaikan dapat dilihat pada Tabel 6 . 
Tabel 4. Hasil Penelitian Tiap Atribut Tingkat Kematangan Proses DS4, DS8 dan DS11

\begin{tabular}{|c|c|c|c|c|c|c|}
\hline \multirow{2}{*}{ Proses } & \multicolumn{6}{|c|}{ Atribut Tingkat Kematangan } \\
\hline & AC & PSP & $\mathbf{T A}$ & SE & $\mathbf{R A}$ & GSM \\
\hline $\begin{array}{l}\text { Memastikan } \\
\text { pelayanan yang } \\
\text { berkesinambungan } \\
\text { (DS4) }\end{array}$ & $\begin{array}{l}\text { Manajemen } \\
\text { memiliki } \\
\text { kepedulian yang } \\
\text { tinggi untuk } \\
\text { memberikan } \\
\text { layanan yang } \\
\text { senantiasa dapat } \\
\text { diakses kapan saja } \\
\text { dan di mana saja } \\
\text { oleh pengguna } \\
\text { SIA }\end{array}$ & $\begin{array}{l}\text { Prosedur proses } \\
\text { jaminan } \\
\text { kelangsungan } \\
\text { layanan pada } \\
\text { implementasi SIA } \\
\text { UNP belum } \\
\text { sepenuhnya } \\
\text { diformalkan. }\end{array}$ & $\begin{array}{l}\text { Perangkat bantu } \\
\text { sudah mulai } \\
\text { digunakan dalam } \\
\text { proses memastikan } \\
\text { pelayanan yang } \\
\text { berkesinambungan } \\
\text { pada implementasi } \\
\text { SIA UNP }\end{array}$ & $\begin{array}{l}\text { Pelatihan bagi staf } \\
\text { pengelola telah } \\
\text { mulai dilakukan } \\
\text { untuk memastikan } \\
\text { keberlangsungan } \\
\text { layanan SIA UNP }\end{array}$ & $\begin{array}{l}\text { Pendelegasian } \\
\text { tanggungjawab } \\
\text { proses memastikan } \\
\text { pelayanan yang } \\
\text { berkesinambungan } \\
\text { pada implementasi } \\
\text { SIA UNP telah } \\
\text { didefinisikan }\end{array}$ & $\begin{array}{l}\text { Manajemen telah } \\
\text { memiliki tujuan } \\
\text { yang jelas terhadap } \\
\text { proses memastikan } \\
\text { pelayanan yang } \\
\text { berkesinambungan } \\
\text { pada implementasi } \\
\text { SIA UNP }\end{array}$ \\
\hline $\begin{array}{l}\text { Pengelolaan } \\
\text { layanan bantu } \\
\text { (DS8) }\end{array}$ & $\begin{array}{l}\text { Menajemen } \\
\text { memiliki } \\
\text { kepedulian yang } \\
\text { cukup besar untuk } \\
\text { memberikan } \\
\text { layanan bantu bagi } \\
\text { pengguna SIA }\end{array}$ & $\begin{array}{l}\text { Prosedur } \\
\text { pengelolaan } \\
\text { layanan bantu pada } \\
\text { implementasi SIA } \\
\text { belum sepenuhnya } \\
\text { diformalkan }\end{array}$ & - & $\begin{array}{l}\text { Pelatihan bagi staf } \\
\text { pengelola layanan } \\
\text { bantu SIA UNP } \\
\text { masih belum } \\
\text { bersifat formal }\end{array}$ & $\begin{array}{l}\text { Tanggungjawab } \\
\text { pengelolaan layanan } \\
\text { bantu pada } \\
\text { implementasi SIA } \\
\text { UNP belum } \\
\text { didefinisikan dengan } \\
\text { baik }\end{array}$ & $\begin{array}{l}\text { Penyelesaian } \\
\text { permasalahan } \\
\text { pengguna tidak } \\
\text { terukur, sehingga } \\
\text { masalah yang } \\
\text { dihadapi pengguna } \\
\text { seringkali tidak } \\
\text { terselesaikan }\end{array}$ \\
\hline $\begin{array}{l}\text { Pengelolaan data } \\
\text { (DS11) }\end{array}$ & $\begin{array}{l}\text { Kepedulian } \\
\text { manajemen } \\
\text { terhadap } \\
\text { pengelolaan data } \\
\text { SIA di setiap unit } \\
\text { kerja UNP sudah } \\
\text { cukup baik }\end{array}$ & $\begin{array}{l}\text { Prosedur } \\
\text { pengelolaan data } \\
\text { SIA UNP belum } \\
\text { sepenuhnya } \\
\text { diformalkan }\end{array}$ & $\begin{array}{l}\text { Alat bantu } \\
\text { pengelolaan data } \\
\text { SIA UNP telah } \\
\text { mulai digunakan, } \\
\text { khususnya untuk } \\
\text { backup, restorasi } \\
\text { dan penghapusan } \\
\text { data }\end{array}$ & $\begin{array}{l}\text { Kegiatan pelatihan } \\
\text { bagi pengelola data } \\
\text { SIA sudah mulai } \\
\text { dilakukan }\end{array}$ & $\begin{array}{l}\text { Tanggungjawab } \\
\text { pengelolaan data } \\
\text { SIA UNP belum } \\
\text { sepenuhnya } \\
\text { terdefinisi secara } \\
\text { jelas }\end{array}$ & $\begin{array}{l}\text { Pengawasan } \\
\text { terhadap } \\
\text { pengelolaan data } \\
\text { SIA UNP belum } \\
\text { sepenuhnya } \\
\text { dilakukan secara } \\
\text { baik }\end{array}$ \\
\hline
\end{tabular}


Tabel 6. Upaya Perbaikan Tiap Atribut Tingkat Kematangan Proses DS4, DS8 dan DS11

\begin{tabular}{|c|c|c|c|c|c|c|}
\hline \multirow{2}{*}{ Proses } & \multicolumn{6}{|c|}{ Atribut Tingkat Kematangan } \\
\hline & $\mathbf{A C}$ & PSP & $\mathbf{T A}$ & SE & RA & GSM \\
\hline $\begin{array}{l}\text { Memastikan } \\
\text { pelayanan yang } \\
\text { berkesinambungan } \\
\text { (DS4) }\end{array}$ & $\begin{array}{l}\text { Menetapkan } \\
\text { indikator dan target } \\
\text { kerja untuk proses } \\
\text { memastikan } \\
\text { keberlangsungan } \\
\text { layanan SIA, } \\
\text { sehingga layanan } \\
\text { dapat diakses setiap } \\
\text { saat }\end{array}$ & $\begin{array}{l}\text { Prosedur formal } \\
\text { untuk memastikan } \\
\text { agar pelayanan dapat } \\
\text { diakses secara } \\
\text { kontinue oleh } \\
\text { pengguna harus } \\
\text { disosialisasikan } \\
\text { secara lebih baik } \\
\text { dalam organisasi }\end{array}$ & $\begin{array}{l}\text { Menggunakan } \\
\text { perangkat bantu } \\
\text { (tools) terbaru } \\
\text { untuk menjamin } \\
\text { keberlangsungan } \\
\text { layanan SIA }\end{array}$ & $\begin{array}{l}\text { Melakukan } \\
\text { pelatihan dan } \\
\text { sertifikasi formal } \\
\text { terkait } \\
\text { keberlangsungan } \\
\text { layanan terhadap } \\
\text { staf }\end{array}$ & $\begin{array}{l}\text { Tanggung jawab } \\
\text { pengelolaan } \\
\text { keberlangsungan } \\
\text { layanan SIA harus } \\
\text { disosialisasikan } \\
\text { secara lebih baik } \\
\text { dalam organisasi, } \\
\text { sehingga dipahami } \\
\text { oleh semua unsur } \\
\text { yang terlibat }\end{array}$ & $\begin{array}{l}\text { Mengembangkan } \\
\text { indikator dan target } \\
\text { kinerja untuk } \\
\text { memastikan agar } \\
\text { layanan dapat } \\
\text { diakses secara } \\
\text { berkesinambungan } \\
\text { oleh pengguna dan } \\
\text { secara rutin } \\
\text { mengukur performa } \\
\text { layanan }\end{array}$ \\
\hline $\begin{array}{l}\text { Pengelolaan } \\
\text { layanan bantu } \\
\text { (DS8) }\end{array}$ & $\begin{array}{l}\text { Menetapkan } \\
\text { indikator dan target } \\
\text { kinerja layanan } \\
\text { layanan bantu dan } \\
\text { mensosialisasikanny } \\
\text { a pada setiap unit } \\
\text { kerja }\end{array}$ & $\begin{array}{l}\text { Prosedur } \\
\text { pengelolaan layanan } \\
\text { bantu } \\
\text { disosialisasikan } \\
\text { secara terus menerus } \\
\text { dalam organisasi }\end{array}$ & $\begin{array}{l}\text { Penanganan } \\
\text { permasalahan } \\
\text { pengguna telah } \\
\text { menggunakan } \\
\text { aplikasi khusus }\end{array}$ & $\begin{array}{l}\text { Melakukan } \\
\text { pelatihan dan } \\
\text { sertifikasi formal } \\
\text { terhadap staf } \\
\text { pengelola layanan } \\
\text { bantu }\end{array}$ & $\begin{array}{l}\text { Tanggung jawab } \\
\text { pengelolaan layanan } \\
\text { bantu didefinisikan } \\
\text { secara jelas serta } \\
\text { disosialisasikan } \\
\text { secara lebih baik } \\
\text { pada setiap unit } \\
\text { kerja }\end{array}$ & $\begin{array}{l}\text { Mengukur performa } \\
\text { layanan bantu } \\
\text { berdasarkan } \\
\text { indikator dan target } \\
\text { kinerja yang telah } \\
\text { ditetapkan. }\end{array}$ \\
\hline $\begin{array}{l}\text { Pengelolaan data } \\
\text { (DS11) }\end{array}$ & $\begin{array}{l}\text { Menetapkan } \\
\text { indikator dan target } \\
\text { kinerja yang } \\
\text { disosialisasikan pada } \\
\text { setiap unit kerja }\end{array}$ & $\begin{array}{l}\text { Prosedur } \\
\text { pengelolaan data } \\
\text { telah diformalkan } \\
\text { dan dikenal secara } \\
\text { luas serta dilakukan } \\
\text { sharing knowledge }\end{array}$ & $\begin{array}{l}\text { Perangkat bantu } \\
\text { (tools) terbaru } \\
\text { mulai } \\
\text { dimanfaatkan } \\
\text { untuk pengelolaan } \\
\text { data }\end{array}$ & $\begin{array}{l}\text { Melakukan } \\
\text { pelatihan dan } \\
\text { sertifikasi formal } \\
\text { terhadap staf } \\
\text { pengelola data }\end{array}$ & $\begin{array}{l}\text { Tanggungjawab } \\
\text { pengelolaan data } \\
\text { didefinisikan secara } \\
\text { jelas, ditetapkan } \\
\text { serta } \\
\text { dikomunikasikan } \\
\text { dalam organisasi }\end{array}$ & $\begin{array}{l}\text { Pengawasan dan } \\
\text { performa indikator } \\
\text { dan target kinerja } \\
\text { dilakukan secara } \\
\text { konsisten terhadap } \\
\text { proses pengelolaan } \\
\text { data }\end{array}$ \\
\hline
\end{tabular}




\section{Kesimpulan, Implikasi dan Saran \\ 1. Kesimpulan}

Berdasarkan hasil penelitian dan pembahasan dapat disimpulkan beberapa hal sebagai berikut:

a. Proses memastikan pelayanan yang berkesinambungan pada implementasi SIA UNP berada pada tingkat kematangan 3 atau proses terdefinisi. Hasil penelitian menunjukkan manajemen memiliki kepedulian yang besar untuk memberikan layanan yang senantiasa dapat diakses kapan saja dan di mana saja oleh pengguna. Kepedulian diwujudkan dengan mendefinisikan tanggungjawab dan prosedur proses memastikan pelayanan yang berkesinambungan. Untuk mencapai tujuan tersebut, penggunaan perangkat bantu dan pelatihan bagi staf pengelola telah mulai dilakukan.

b. Proses pengelolaan layanan bantu pada implementasi SIA UNP berada pada tingkat kematangan 3 atau proses terdefinisi. Hal ini menunjukkan adanya kepedulian yang cukup besar dari manajemen untuk memberikan layanan bantu bagi pengguna SIA dengan menetapkan prosedur dan tanggungjawab pengelolaan layanan bantu pada implementasi SIA UNP. Penyelesaian permasalahan telah dilakukan walaupun belum terukur, pelatihan bagi staf pengelola layanan bantu SIA UNP telah dilakukan namun belum bersifat formal.

c. Proses pengelolaan data pada implementasi SIA UNP berada pada tingkat kematangan 3 atau proses terdefinisi. Hal ini menunjukkan kepedulian manajemen terhadap pengelolaan data SIA sudah cukup baik yang diwujudkan dengan penetapan tanggungjawab dan prosedur pengelolaan data. Alat bantu sudah mulai digunakan untuk pengelolaan data SIA, khususnya untuk backup, restorasi dan penghapusan data. Pelatihan untuk staf pengelola data juga telah mulai dilakukan, serta telah dilakukan pengawasan terhadap pengelolaan data walaupun belum optimal.

\section{Implikasi}

a. Implikasi Praktis

Hasil penelitian mengindikasikan semakin tinggi tingkat kematangan setiap proses TI pada implementasi SIA UNP akan memberikan manfaat yang besar bagi pengguna. Ini artinya perlu usaha untuk memastikan agar setiap atribut yang mempengaruhi tingkat kematangan proses TI dapat dilakukan secara optimal.

b. Implikasi Kebijakan

Penelitian ini berimplikasi pada kebijakan yang perlu diambil pihak manajemen untuk menciptakan layanan SIA yang lebih optimal. Berdasarkan hasil penelitian, dapat diketahui faktor-faktor yang masih memiliki sisi lemah. Kebijakan yang dapat diambil antara lain menetapkan prosedur, sosialisasi prosedur, penggunaan dan pemanfaatan perangkat bantu serta peningkatan SDM untuk mendukung implementasi SIA pada setiap proses TI. 
c. Implikasi Pengembangan

Dengan mengetahui tingkat kematangan beberapa proses TI terkait penyampaian dan dukungan layanan SIA pada saat ini, manajemen UNP dapat melakukan evaluasi secara menyeluruh terhadap semua proses TI pada implementasi SIA UNP. Evaluasi dapat mengidentifikasi kelemahan-kelemahan tiap proses TI pada implementasi SIA UNP, sehingga dapat ditentukan upaya perbaikan yang harus dilakukan untuk menciptakan tata kelola SIA yang efektif. Tata kelola SIA yang efektif akan memberi manfaat yang besar baik bagi lembaga maupun bagi seluruh pengguna.

\section{Saran}

a. Hasil penelitian ini diharapkan dapat memberikan gambaran umum tentang tingkat kematangan proses Delivery and Support pada implementasi SIA di UNP sebagai dasar untuk melakukan evaluasi menyeluruh dalam upaya membenahi tata kelola SIA di UNP;

b. Perlu dilaksanakan evaluasi tingkat kematangan secara menyeluruh terhadap semua proses yang diisyaratkan dalam kerangka kerja COBIT pada implementasi SIA UNP;

c. Evaluasi tingkat kematangan setiap proses Delivery and Support pada implementasi SIA UNP ini disarankan dapat dilakukan secara rutin setiap periode waktu tertentu (secara periodik), agar tingkat kematangan yang diinginkan dapat dicapai.

d. Pengawasan dan sosialisasi terkait aturan, kebijakan dan prosedur SIA perlu dilakukan secara menyeluruh baik perencanaan maupun implementasinya. Dengan demikian diharapkan implementasi SIA dapat memberi manfaat yang besar bagi pengguna dan lembaga.

\section{E. Referensi}

[1] IT Governance Institute. (2006), Cobit Mapping Overview International IT Guidance, 2nd Edition. IT Governance Institute.

[2] IT Governance Institute. (2007). IT Assurance Guide: Using COBIT. Diakses dari http://www.inf.unideb.hu/ fazekasg/english/Information_System \%27s Control_COBIT/IT\%20Assurance\%20Guide\%20-\%20COBIT \%204.1\% 20\%282007\%29.pdf, pada tanggal 1 Januari 2013.

[3] Pederiva, A. (2003). The CobIT Maturity Model in a Vendor Evaluation Case. Information System Control Journal, Volume 3, 2003.

[4] Sukardi. (2009). Metodologi Penelitian Pendidikan. Jakarta: PT. Bumi Aksara.

[5] Surendro, Kridanto. (2009). Implementasi Tata Kelola Teknologi Informasi. Bandung: Informatika Bandung

[6] UPT. Puskom UNP. (2012). Laporan Tahunan TIM ICT UNP Tahun 2012. Padang: UNP Padang. 